\title{
Kualitas Sumber Daya Manusia, Profesionalisme Kerja, Dan Komitmen Sebagai Faktor Pendukung Peningkatan Kinerja Karyawan PDAM Kabupaten Jember
}

\section{(Quality of Human Resources, Labour profesionalisme, and commitment as a factor Supporting Employee Performance Improvement PDAM Jember)}

\author{
Merisa Fajar Aisyah, Wiji Utami ${ }^{1}$, Sunardi, Sudarsih \\ Jurusan Manajemen, Fakultas Ekonomi, Universitas Jember (UNEJ) \\ Jln. Kalimantan 37, Jember 68121 \\ E-mail:wiji.fe@unej.ac.id
}

\begin{abstract}
Abstrak
Penelitian ini bertujuan untuk mengetahui kualitas sumber daya manusia, profesionalisme kerja, komitmen dan pengaruhnya terhadap kinerja karyawan PDAM Kabupaten Jember baik secara parsial maupun simultan. Pendekatan riset yang digunakan dalam penelitian ini adalah pendekatan kuantitatif. Populasi yang ada dalam perusahaan sebesar 150 karyawan tetap dan diambil 75 orang sebagai responden dengan metode pengambilan sampel yang digunakan adalah simple random sampling atau sampel acak sederhana dengan cara lotre/undian dari nama-nama karyawan PDAM Kabupaten Jember yang kemudian diambil undian sebanyak sampel yang dipakai yaitu 75 nama karyawan yang terpilih didalam pengundian. Metode analisis data menggunakan analisis regresi linier berganda. Hasil pengujian dan analisis yang dilakukan menyatakan bahwa kualitas sumber daya manusia berpengaruh positif dan signifikan terhadap kinerja karyawan PDAM Kabupaten Jember, profesionalisme kerja berpengaruh positif dan signifikan terhadap kinerja karyawan PDAM Kabupaten Jember dan komitmen berpengaruh positif dan signifikan terhadap kinerja karyawan PDAM Kabupaten Jember. Secara simultan kualitas sumber daya manusia, profesionalisme kerja, dan komitmen mendukung kinerja karyawan PDAM Kapubaten Jember.
\end{abstract}

Kata Kunci: kualitas sumber daya manusia, profesionalisme kerja, komitmen dan kinerja karyawan.

\section{Abstract}

This study aims to determine the effect of human resource quality, professionalism of work, commitment to employee performance PDAM Jember partially and simultaneously. Research approach used in this study is quantitative. Population in the company amounted to 150 and taken 75 respondents to use the sample with the sampling method is simple random sampling or simple random sample by means of a lottery / raffle of names of employees PDAM Jember is then taken as samples used lottery of 75 names of employees Selected in the draw. Methods of analysis using multiple linear regression analysis were used to determine the influence of strong between the dependent variable and independent variables. The test results and analysis conducted states that the variable quality of human resources and a significant positive effect on employee performance PDAM Jember Regency. Variable professionalism and significant positive effect on employee performance PDAM Jember. And variable commitment and significant positive effect on employee performance PDAM Jember. And the quality of human resources, professionalism, and commitment to simultaneously positive and significant influence on employee performance PDAM Jember Regency.

Keywords: Human resource quality, professionalism of work, commitment, and performance of employees.

\section{Pendahuluan}

Air merupakan hal penting yang ada di bumi, tanpa adanya air tidak akan ada kehidupan. Aktivitas manusia sangat membutuhkan air yang bersih untuk keperluan hidup seharihari, pertanian, air minum, dan industri. Pertumbuhan masyarakat yang semakin meningkat menyebabkan bertambahnya pertumbuhan industri, sehingga sumbersumber air tercemar oleh limbah industri. Jumlah air bersih yang sangat relatif sedikit dibanding dengan keperluan air yang dibutuhkan, maka mendorong Pemerintah Daerah untuk mengolah air kotor menjadi air bersih yang memenuhi syarat kesehatan bagi masyarakat.

Pemerintah Daerah Kabupaten Jember kemudian mendirikan Perusahaan Daerah Air Minum di Kabupaten Jember dengan tujuan untuk menambah penghasilan daerah, pembangunan daerah dalam arti luas dan pembangunan ekonomi nasional umumnya dalam rangka meningkatkan kesejahteraan rakyat dan memenuhi kebutuhan ketenagakerjaan dalam perusahaan menuju masyarakat adil dan makmur. Perusahaan Daerah Air Minum berusaha memenuhi kebutuhan air bersih kepada masyarakat, dengan mengolah air bersih menjadi air minum, pelayanan diberikan dengan tujuan untuk meningkatkan kesejahteraan hidup karena kurangnya air bersih banyak mengakibatkan wabah penyakit. Perusahaan Daerah Air Minum dalam mendistribusikan produk berhubungan langsung dengan masyarakat, maka dibutuhkan sumber daya manusia yang memiliki kinerja yang baik. Menurut Mangkunegara (2006:67) kinerja karyawan atau prestasi karyawan merupakan hasil kerja secara kualitas dan kuantitas

1 Corresponding Author 
yang dicapai seorang karyawan dalam melaksanakan tugasnya sesuai tanggung jawab yang diberikan kepadanya. Untuk meningkatkan kinerja karyawan dibutuhkan banyak variabel yang mendukung, antara lain kualitas sumber daya manusia, profesionalisme kerja dan komitmen. Widodo (dalam Kharis, 2010:8) sumber daya manusia dapat dikatakan berkualitas manakala mereka mempunyai kemampuan untuk melaksanakan kewenangan dan tanggung jawab yang diberikan kepadanya. Kemampuan tersebut hanya dapat dicapai manakala mereka mempunyai bekal pendidikan, latihan dan pengalaman yang cukup memadai untuk melaksanakan tugas dan tanggung jawab yang diberikan. Apabila karyawan tidak memiliki kualitas yang baik makaakan mempengaruhi kinerja yang dihasilkan dan akan berdampak pada perusahaan.

Setiap karyawan dianjurkan untuk bisa memiliki sikap profesionalisme dalam bekerja agar bisa mengoptimalkan skill, waktu, tenaga, ilmu pengetahuan dan sumber daya yang dimilikinya sesuai dengan bidang yang dijalani, sehingga akan berpengaruh terhadap kinerja yang dilakukan oleh karyawan. Menurut Siagian (2009:163) profesionalisme adalah keandalan dan keahlian dalam pelaksanaan tugas sehingga terlaksana dengan mutu tinggi, waktu yang tepat, cermat, dan dengan prosedur yang mudah dipahami.

Karyawan yang berkualitas serta profesional harus memiliki komitmen terhadap perusahaannya. Karyawan berjanji pada dirinya sendiri untuk bisa memajukan perusahaan agar tercapai sebuah tujuan bersama dengan kinerja yang sebaik mungkin dalam kondisi persaingan global dewasa ini, karena komitmen juga merupakan keterikatan individu pada suatu perusahaan. Menurut pendapat Robbins (2002:140) komitmen pada organisasi merupakan suatu keadaan dimana seorang karyawan memihak pada organisasi dan tujuantujuannya, serta berniat memelihara keanggotaan dalam organisasi itu. Dengan memiliki komitmen yang tinggi pada suatu perusahaan maka akan meningkatkan kinerja yang baik pada perusahaan tersebut. Karyawan di PDAM memiliki komitmen terhadap perusahaan dengan mereka memberikan pelayanan yang baik dan memberikan hasil kinerjanya secara maksimal terhadap perusahaan, bersungguh-sungguh dalam bekerja, dan mempertahankan dirinya untuk tetap bekerja di perusahaan.

Perusahaan Daerah Air Minum (PDAM) Kabupaten Jember merupakan perusahaan yang bergerak pada usaha penyedia air bersih yang ada dalam naungan Badan Usaha Milik Daerah (BUMD), dengan lokasi di Jalan Trunojoyo 73 Jember. Perusahaan Daerah Air Minum Jember dituntut untuk meningkatkan pelayanan demi mewujudkan kepuasan pelanggan dan menciptakan citra dirinya. Untuk mewujudkan hal tersebut diperlukan kinerja yang baik dari karyawan. Tujuannya agar terjalin kerja sama yang baik antar pengguna jasa dan pihak Perusahaan Daerah Air Minum.

Saat ini perusahaan menggunakan alat canggih sistem absen (check clock) untuk mendeteksi kehadiran karyawan sehingga karyawan memiliki rasa tanggung jawab dan tepat waktu dalam kehadirannya. Hal tersebut dilakukan agar karyawan bisadisiplin sehingga harapannya kinerja juga akan meningkat. Salah satu unsur untuk meningkatkan Kinerja karyawan adalah mutu atau kualitas sumber daya yang baik pada karyawan tersebut dan sikap profesionalisme dalam menjalankan tugas dan aturan yang ada, serta komitmen karyawan yang dimilikinya terhadap perusahaan untuk mewujudkan tujuan perusahaan.

Sibagariang (2008) dalam penelitiannya mengungkapkan bahwa kualitas sumber daya manusia tidak berpengaruh signifikan terhadap kinerja. Pendapat tersebut berbeda dengan penelitan Sitohang (2009), Kasannudin (2011), yang mengatakan bahwa kualitas sumber daya manusia memiliki pengaruh signifikan terhadap kinerja. Kemudian Cahyani (2007), mengatakan bahwa profesionalisme dan komitmen organisasi berpengaruh terhadap kinerja karyawan, pendapat serupa juga diungkapkan Wulandari (2014) dan Fadliyansya (2013).

Peneitian ini bertujuan untuk melakukan pengujian terhadap pengaruh kualitas Sumber Daya Manusia, profesionalisme kerja dan komitmen terhadap kinerja karyawan. Diharapkan nantinya hasil penelitian ini menjadi pedoman perusahaan untuk mendukung dan memotivasi karyawan didalam meningkatkan kualitas dirinya, menumbuhkan jiwa profesionalisme dan meningkatkan komitmen terhadap perusahaan guna meningkatkan kinerjanya.

\section{Metode}

\section{Rancangan Penelitian}

Rancangan penelitian yang digunakan dalam penelitian ini adalah explanatory research yaitu penelitian yang bertujuan untuk menguji suatu teori atau hipotesis guna memperkuat atau bahkan menolak teori.

\section{Jenis dan Sumber Data}

Data yang digunakan dalam penelitian ini adalah data primer yang diperoleh dari wawancara dan penyebaran kuisioner. Data sekunder dalam penelitian ini diperoleh secara tidak langsung melalui buku bacaan yang terkait dengan variabel yang diteliti, data yang diperoleh dari internet, dan jurnaljurnal yang ada.

\section{Populasi dan Sampel}

Populasi yang ada dalam perusahaan sebesar 150 orang dan diambil 75 responden sebagai sampel dengan metode pengambilan sampel yaitu simple random sampling atau tehnik pengambilan sampel secara acak sederhana.Tehnik mendapatkan responden adalah dengan cara lotre atau mengundi nama-nama karyawan PDAM Kabupaten Jember yang kemudian diambil sebanyak sampel yang dipakai yaitu 75 nama karyawan.

\section{Metode Analisis Data}

Alat analisis yang digunakan untuk menyelesaikan permasalahan yang ada adalah regresi linier berganda.

\section{Hasil dan Pembahasan}

\section{Analisis Regresi Linier Berganda}

Analisis regresi linier berganda berkaitan dengan studi ketergantungan suatu variabel dependen pada satu atau lebih variabel independen dengan tujuan untuk mengetahui seberapa besar pengaruh variabel independen terhadap variabel dependen. Hasil analisis regresi linear berganda antara variabel independen yaitu kualitas SDM, profesionalisme kerja, dan komitmen, serta variabel dependen yaitu kinerja disajikan pada Tabel 1 berikut: 
Tabel 1. Hasil estimasi Regresi

\begin{tabular}{|c|c|c|c|c|}
\hline Variabel & Koefisien & t-hitung & Sig & Ket \\
\hline (Constant) & 0,062 & & & \\
\hline $\begin{array}{l}\text { Kualitas } \\
\text { (X1) }\end{array}$ & 0,374 & 3,633 & 0,001 & Sig \\
\hline $\begin{array}{l}\text { Profesionalisme } \\
\text { (X2) }\end{array}$ & 0,268 & 2,650 & 0,006 & Sig \\
\hline Komitmen (X3) & 0,308 & 3,130 & 0,003 & Sig \\
\hline $\begin{array}{l}\text { R Square }=0,738 \\
\text { Signifikansi }=5 \%\end{array}$ & & & & \\
\hline
\end{tabular}

Sumber : data primer,2015.

Berdasarkan koefisien regresi, maka persamaan regresi yang dapat dibentuk adalah:

$$
\mathrm{Y}=0,062+0,374 \mathrm{X}_{1}+0,268 \mathrm{X}_{2}+0,308 \mathrm{X}_{3}
$$

a. Koefisien regresi dari konstanta diperoleh nilai sebesar 0,062 dengan tanda positif, angka ini memberikan arti bahwa tanpa adanya kualitas sumber daya manusia, profesionalisme kerja, dan komitmen maka akan menurunkan kinerja karyawan PDAM Kabupaten Jember.

b. Koefisien regresi dari kualitas sumber daya manusia memiliki pengaruh signifikan terhadap kinerja dengan arah yang positif sebesar 0,374 . Hal ini berarti bahwa, jika kualitas sumber daya manusia semakin baik maka akan diikuti dengan meningkatnya kinerja karyawan PDAM Kabupaten Jember.

c. Koefisien regresi dari profesionalisme kerja memiliki pengaruh signifikan terhadap kinerja dengan arah yang positif sebesar 0,268. Hal ini berarti bahwa, jika profesionalisme kerja semakin baik maka akan diikuti dengan meningkatnya kinerja karyawan PDAM Kabupaten Jember.

d. Koefisien regresi komitmen memiliki pengaruh signifikan terhadap kinerja dengan arah yang positif sebesar 0,308. Hal ini berarti bahwa, jika komitmen semakin baik maka akan diikuti dengan meningkatnya kinerja karyawan PDAM Kabupaten Jember.

\section{Uji t}

Pengujian ini dilakukan untuk mengetahui apakah secara parsial variabel independen berpengaruh signifikan terhadap variabel dependen. Tabel distribusi t dicari pada $\alpha=5 \%$ (uji 2 sisi, $0,05: 2=0,025$ ), dengan derajat kebebasan (df) n-k-1 atau 75-3-1 =71. Berdasarkan pengujianuji t, diperoleh hasil;

a. kualitas SDM $\left(X_{1}\right)$ memiliki nilai $t_{\text {hitung }}>t_{\text {tabel }}$ yaitu $t$ 3,633 $>1,994$ dan signifikasi $0,001<0,05$, maka Ho ditolak dan Ha diterima, berarti secara parsial variabel kualitas SDM berpengaruh signifikan terhadap kinerja karyawan PDAM Kabupaten Jember;

b. profesionalisme kerja $\left(\mathrm{X}_{2}\right)$ memiliki $t_{\text {hitung }}>t_{\text {tabel }}$ yaitu nilai t 2,650 > 1,994 dan signifikasi $0,006<0,05$, maka Ho ditolak dan Ha diterima, berarti secara parsial variabel profesionalismekerja berpengaruh signifikan terhadap kinerja karyawan PDAM Kabupaten Jember; c. komitmen $\left(\mathrm{X}_{3}\right)$ memiliki $\mathrm{t}_{\text {hitung }}>\mathrm{t}_{\text {tabel }}$ yaitu nilai t $3,150>$ 1,994 dan signifikasi $0,008<0,05$, maka Ho ditolak dan Ha diterima,secara parsial variabel komitmen berpengaruh signifikan terhadap kinerja karyawan PDAM Kabupaten Jember.

\section{Uji F}

Uji $\mathrm{F}$ dimaksudkan untuk mengetahui pengaruh kualitas SDM, profesionalisme kerja, dan komitmen terhadap kinerja karyawan secara simultan. Tabel distribusi $\mathrm{F}$ dicari pada $\alpha=$ $5 \%$, dengan derajat kebebasan (df) df1 atau 4-1 = 3, dan df2 n-k-1 atau 75-3-1 = 71. Hasil pengujian menunjukkan bahwa $F_{\text {hitung }}>F_{\text {tabel }}(66,687>2,73)$ dan signifikasi $(0,000<0,05)$, maka Ho ditolak dan Ha diterima, artinya kualitas SDM, profesionalisme kerja, dan komitmen secara simultan berpengaruh signifikan terhadap kinerja karyawan PDAM Kabupaten Jember.

\section{Pembahasan}

Hasil pengujian koefisien dari analisis regresi linear berganda, menunjukkan kualitas SDM, profesionalisme kerja, dan komitmen berpengaruh secara parsial dan simultan terhadap kinerja karyawan PDAM Kabupaten Jember. Hasil pengujian koefisien dari analisis regresi linear berganda, menunjukkan bahwa kualitas SDM, profesionalisme kerja, dan komitmen berpengaruh signifikan terhadap kinerja karyawan PDAM Kabupaten Jember dengan arah positif. Berdasarkan hasil pengujian tersebut, maka dapat disimpulkan bahwa hipotesis yang menyatakan, "ada pengaruh kualitas SDM, profesionalisme kerja, dan komitmen terhadap kinerja karyawan PDAM Jember" diterima. Hal ini mengindikasikan bahwa jika kualitas SDM, profesionalisme kerja, dan komitmen, memiliki nilai positif, maka akan memberikan pengaruh dalam meningkatkan kinerja karyawan PDAM Kabupaten Jember.

\section{Pengaruh Kualitas SDM Terhadap Kinerja Karyawan}

Penelitian yang dilakukan, menunjukkan bahwa nilai koefisien variabel kualitas SDM sebesar 0,374 atau 37,4\% dengan arah positif. Dapat dijelaskan bahwa sumber daya manusia dapat dikatakan berkualitas manakala mereka mempunyai kemampuan untuk melaksanakan kewenangan dan tanggung jawab yang diberikan kepadanya. Kemampuan tersebut hanya dapat dicapai ketika mereka mempunyai bekal pendidikan, latihan dan pengalaman yang cukup memadai untuk melaksanakan tugas dan tanggung jawab yang diberikan (Widodo dalam Kharis 2010:8). Penelitian ini mendukung penelitian Kasanudin (2011) dan Sitohang (2009), bahwa kualitas SDM berpengaruh terhadap kinerja karyawan PDAM Sedangkan penelitian ini memberikan hasil yang berbeda dengan penelitian Sibagariang (2008) yang menyatakan kualitas SDM tidak memiliki pengaruh terhadap kinerja karyawan, dikarenakan penempatan karyawan pada obyek penelitian Sibagarian tidak sesuai dengan latar belakang pendidikannya, sehingga menyebabkan pekerjaan yang ditanganinya tidak sesuai dengan yang diharapkan dan pada akhirnya akan mempengaruhi kinerja pada perusahaan. Kualitas sumber daya manusia dapat dilihat dengan adanya karyawan yang bekerja sebaik mungkin untuk membawa organisasi menjadi lebih baik.Karyawan juga memiliki sikap dan perilaku baik terhadap organisasisehingga etika dalam perusahaan maupun terhadap pengguna jasa terjaga dengan baik. Karyawan yang berkerja di PDAM memiliki hubungan 
baik dengan karyawan lainnya.Hubungan baik yang ada diharuskan tetap terjaga oleh setiap karyawannya baik terhadap rekan kerja maupun terhadap pengguna jasa.Karyawan juga dituntut lebih fleksibel didalam berkomunikasi, baik komunikasi formal maupun informal atau secara langsung maupun tidak langsung. Dengan adanya hubungan baik yang ditunjang dengan komunikasi yang fleksibel maka kegiatan kerjadidalam lingkungan PDAM dapat dilaksanakan dengan baik, seperti merencanakan kerja yang berhubungan dengan anggaran dan operasi di bidang pelayanan.

Komunikasi antar karyawan dapat dibangun dengan saling menghargai pendapat baik saat diskusi, rapat ataupun dalam kegiatan yang bersifat informal. Komunikasi merupakan hal penting karena dengan komunikasi kualitas sumber daya manusia akan lebih jelas nampak dan dapat ditransfer kepada karyawan lain, sehingga kualitas SDM akan meningkat.

\section{Pengaruh Profesionalisme Kerja Terhadap Kinerja Karyawan}

Penelitian yang dilakukan, menunjukkan bahwa nilai koefisien variabel profesionalisme kerja sebesar 0,268 atau $26,8 \%$ dengan arah positif. Siagian (2009:163) menyatakan profesionalisme adalah keandalan dan keahlian dalam pelaksanaan tugas sehingga terlaksana dengan mutu tinggi, waktu yang tepat, cermat, dan dengan prosedur yanng mudah dipahami dan diikuti oleh pelanggan. Hasil penelitian ini sejalan dengan yang diungkapkan oleh Cahyani (2007) adanya sikap yang profesionalisme, menjadikan diri seorang untuk bersikap dan berperilaku dengan baik dan akan meningkatkan kinerja yang dihasilkannya, sehingga profesionalisme kerja memiliki pengaruh terhadap kinerja pada karyawan di dalam perusahaan. Karyawan dari PDAM juga harus ulet, berintegritas dan konsekuen didalam pekerjaan atau profesinya. Karyawan berusaha selalu menyelesaikan tugas dengan hasil maksimal sehingga tercapai kinerja yang baik dengan standart mutu yang ditetapkan perusahaan.Karyawan juga bekerja dengan tingkat kelitian yang tinggisehingga bisa meminimalkan kesalahan.

Sikap profesionalisme juga ditunjukkan dengan tidak mudahputus asa serta selalu patuh pada prosedur yang sudah ditetapkan perusahaan.

\section{Simpulan dan Saran}

\section{Kesimpulan}

Berdasarkan hasil analisis yang telah dilakukan pada penelitian ini, maka dapat ditarik kesimpulan sebagai berikut:

Kualitas SDM berpengaruh positif dan signifikan terhadap kinerja karyawan PDAM Jember. Hal ini membuktikan bahwa kualitas SDM yang baik, memiliki prilaku baik, dapat berkomunikasi secara fleksibel, dan dapat berhubunganbaik antara karyawan satu dengan lainnya maka akan memberikan pengaruh dalam meningkatkan kinerja karyawan;

Profesionalisme kerja berpengaruh positif dan signifikan terhadap kinerja karyawan PDAM Jember. Hal ini membuktikan bahwa adanya profesionalisme kerja yang berprinsip pada efektif dan efisien, berintegritas dan konsekuen maka akan memberikan pengaruh dalam meningkatkan kinerja karyawan;
Komitmen berpengaruh positif dan signifikan terhadap kinerja karyawan PDAM Jember. Hal ini membuktikan bahwa adanya komitmen karyawan didalam berkerjaakan memberikan pengaruh dalam meningkatkan kinerja karyawan.

Kualitas SDM, profesionalisme kerja, dan komitmen secara simultan berpengaruh positif dan signifikan terhadap kinerja karyawan PDAM Jember.

\section{Keterbatasan Penelitian}

Penelitian ini masih memiliki keterbatasan serta kekurangan yaitu sebagai berikut:

Penelitian ini hanya menggunakan 3 variabel independen untuk mengukur kinerja karyawan di PDAM Kabupaten Jember, sedangkan masih ada beberapa variabel lain yaitu seperti motivasi, lingkungan kerja yang bisa digunakan untuk mengukur kinerja karyawan di PDAM Kabupaten Jember. Jadi di dalam penelitian ini masih membutuhkan informasi tambahan terkait tentang variabel lain yang digunakan untuk dapat mengukur kinerja karyawan di PDAM Kabupaten Jember.

Penelitian ini hanya dilakukan pada karyawan PDAM Kabupaten Jember saja, sehingga hasil penelitian ini tidak dapat diterapkan di perusahaan lain.

\section{Referensi}

Cahyani, Nur. 2007. “Analisis Pengaruh Profesionalisme Pemeriksaan Pajak, Kepuasan Kerja Dan Komitmen Organisasi Terhadap Kinerja Karyawan”. Tesis. Semarang: Universitas Diponegoro Semarang. http://eprints.undip.ac.id/18439/1/Nur_Cahyani.pdf

Fadliyansya, Fajar. 2013. "Pengaruh Kecerdasan Emosional Terhadap Komitmen dan Kinerja Karyawan Pada Rumah Sakit Islam”. Skripsi. Tidak Dipublikasikan. Lumajang. Universitas Jember.

Kasannudin, Mukhamad. 2011. "Pengaruh Kualitas Sumber Daya Manusia (SDM) Pengelola Koperasi Terhadap Kinerja Koperasi Pondok Pesantren Di Kabupaten Demak". Skripsi. Semarang: Institute Agama Islam Negeri Walisongo Semarang http://library.walisongo.ac.id/digilib/files/disk1/132/jtptiain-gdlmukhamadka-6600-1-pengaruh-p.pdf

Kharis, Abdul. 2010. "Pengaruh Kualitas Sumber Daya Manusia Terhadap Pelaksanaan Sistem Pengendalian Intern Pada Pt.Avia Avian". Skripsi. Universitas Pembangunan Nasional "VETERAN". http://www.google.com/url?sa=tHYPERLINK "http://www.google.com/url? $s a=t \& r c t=j \& q=\&$ esrc $=s \&$ source $=w e b \& c d=2 \& v e d=0 C B 0 Q F j A B \& u$ $r l=h t t p: / / c o r e . a c . u k: 8081 /$ download/pdf/12215856.pdf\&ei=n3ICVfms Ns6XuATn7IH4CQ\&usg=AFQjCNGWLNqKudsFb3HRvjRW_VfE38 Ed9Q\&sig2=ILihy3CLRnN4YJw-ZIwrtw"

Mangkunegara, A.P. 2006. Manajemen Sumber Daya Manusia Perusahaan. Bandung: Rosda.

Robbins, Stephen P. 2006. Perilaku Organisasi. Jakarta: PT Indeks Kelompok Gramedia.

Robbins, Stephen P. 2002. Perilaku Organisasi Versi Bahasa Indonesia. Edisi VIII. Jakarta Prehallindo.

Siagian, Sondang P. 2009. Adminitrasi Pembangunan. Jakarta: Bumi Aksara.

Sibagariang, Arisonaldi. 2013. "Pengaruh Kualitas Sumber Daya Manusia, Komunikasi, Sarana Pendukung Dan Komitmen Organisasi Terhadap Kinerja SKPD (Studi Empiris Pada Pemerintah Kota Sibolga)". Skripsi. Padang: Universitas Negeri Padang.

http://www.google.com/url sa=tHYPERLINK"http://www.google.com/url? $s a=t \& r c t=j \& q=\&$ esrc $=s \&$ source $=w e b \& c d=1 \& v e d=0 C B 4 Q F j A A \& u$ $r l=h t t p: / / e j o u r n a l . u n p . a c . i d / s t u d e n t s / i n d e x . p h p / a k t / a r t i c l e / d o w n l o a d /$ $61 / 49 \&$ ei $=$ XUCVeDAAZOTuASqnoHwCQ\&usg $=$ AFQjCNGIwklJoIKA $\bar{A} Q B q-Q E B N V E X$ - 
$n U \_Q \& \operatorname{sig} 2=8 Y d y k Q n V Y T B u Y Q S 3 w u L v 0 w \& b v m=b v .88198703, d . c 2$

Sitohang, Sonang. 2009. "Pengaruh Kualitas Sumber Daya Manusia Terhadap Kinerja Pengrajin Sentra Industri Kecil Tenun Ikat”. Jurnal: Sekolah Tinggi Ilmu Ekonomi Surabaya.

http://www.google.com/url?sa=tHYPERLINK

"http://www.google.com/url?

$s a=t \& r c t=j \& q=\& e s r c=s \&$ source $=w e b \& c d=1 \& v e d=0 C B s Q F j A A \& u$ $r l=h t t p: / / w w w . s t i e s i a . a c . i d / j u r n a l / i n d e x . p h p / a r t i c l e / d o w n l o a d \_s e l e c t i$ on article $/ 2 / 20130731004 / 1 \&$ ei $=F H c C V b K-E c 6 I u w T-$ $m \overline{4 H I B Q \& u s g}=$ AFQjCNGoXo6P-

h7E2qmYOhn95eA7LT3lug\&sig2 $=a-$

FzKvNgpTiI_WXyPTbFWQ\&bvm $=b v .88198703$, d.c $2 E^{\prime \prime}$

Universitas Jember. 2012. Pedoman Penulisan Karya Ilmiah. Jember: Badan Penerbit Universitas Jember. 